\title{
Physicochemical and Sensory Quality of Brown Sugar: Variables of Processing Study
}

\author{
Raphael Della Maggiore Orlandi ${ }^{1}$, Marta Regina Verruma-Bernardi ${ }^{1}$, Simone Daniela Sartorio ${ }^{1}$ \\ $\&$ Maria Teresa Mendes Ribeiro Borges ${ }^{1}$ \\ ${ }^{1}$ Department of Agroindustrial Technology and Rural Socieconomy, Federal University of São Carlos School \\ (CCA), Araras, SP, Brazil \\ Correspondence: Raphael Della Maggiore Orlandi, Department of Agroindustrial Technology and Rural \\ Socieconomy, Federal University of São Carlos School (CCA), Rodovia Anhanguera, km 174, Mail Box 153, \\ Zip Code: 13600-970, Araras, SP, Brazil. Tel: 55-0169-9235-6010. E-mail: raphael.dmo@gmail.com
}

$\begin{array}{ll}\text { Received: October 29, } 2016 & \text { Accepted: December 8, } 2016 \quad \text { Online Published: January 15, } 2017 \\ \text { doi:10.5539/jas.v9n2p115 } & \text { URL: http://dx.doi.org/10.5539/jas.v9n2p115 }\end{array}$

The research is financed by FAPESP (2012/20234-3).

\begin{abstract}
The lack of standardization in the processing of brown sugar reflects in its physicochemical and sensory quality and, consequently, harms the small producers and cottage industries in the products commercialization. In this context, this work aimed to study the influence of the variables - period of the year, variety of sugar cane, $\mathrm{pH}$ and final temperature of juice cooking - on the acquisition of a product that is acceptable according to the physicochemical and sensory requisites. The physicochemical parameters of the sugars that best classified the product presented juice neutral $\mathrm{pH}(7.0)$ and finalization temperature at $118{ }^{\circ} \mathrm{C}$ for both varieties, in the late period. In the sensory aspect, the sugars of the variety RB92579 found, in a general context, greater acceptance, being classified, also by the judges, as sugars of a darker appearance, smaller granules, less intense sweet aroma and flavor, and high solubility.
\end{abstract}

Keywords: temperature, $\mathrm{pH}$, sugar cane variety

\section{Introduction}

The brown sugar, contrary to the refined one, does not go through a large number of chemical process; therefore, customers consider it as a more natural substitute compared to the white sugar.

The brown sugar is the raw, moist and dark sugar obtained after the sugar cane dehydration. Since it does not go through a refining process, it maintains the calcium and the iron, in addition to other vitamins and minerals.

According to Mendonça et al. (2000), the brown sugar aims the group of people with eating habits based on the minimization or absence of chemical products during the food processing.

This type of sugar is easily recognized by its color and flavor, which are similar to panela or even of the sugar cane juice. This characteristic is due to the fact that the brown sugar does not go through more elaborated processes of juice clarification.

Verruma-Bernardi et al. (2010) evaluated the sensorial characteristics and the preference for brown sugar brands, which showed some differences regarding their appearance and texture.

The the brown sugar color is one of the main attributes that influence purchase, according to Lopes and Borges (1998), and it can be modified according to the differences of temperature and juice $\mathrm{pH}$ during the product processing.

In another study made with brown sugar brands, Verruma-Bernardi et al. (2007) emphasize the lack of standardization in the product elaboration, which proves the sugars sensory variability and the occurrence of a high percentage of moisture and reduced sugars in the analyzed samples - aspects that would consequently affect their shelf life.

According to Durán-Rojas et al. (2012), the lack of standardization in the brown sugar production process harms 
its market positioning, what leads to the rejection of the product by the customer.

Studies by Mosquera et al. (2007) and Mujica et al. (2008) reinforce the importance of process standardization and the study of variables that influence the production of brown sugar. Among the variables they mentioned, the process temperature, $\mathrm{pH}$ of the juice, variety of sugarcane, climate, soil, mode of extraction and the juice cleaning. Mujica et al. (2008), demonstrate in their study the influence of temperature and sugarcane variety, they show the final $\mathrm{pH}$ differences, reducing sugars contents, moisture, color, and shelf life of the product.

The objective of this work was to produce brown sugars and evaluate the sensorial and physical-chemical quality, by combining 4 factors: time of year, variety of sugarcane, the juice $\mathrm{pH}$ and final process temperature.

The time of year (the age of sugarcane), is related to the quantity of Reducing Sugars present in the raw material. The different physiological properties of sugar cane, may influence the chemical attributes and consequently the quality of sugar.

The $\mathrm{pH}$ of the juice and the final process temperature, influence together the acquisition of a sensorially attractive and chemical properties that increase its quality and shelf life. Generally this proprieties are related with the moisture, amount of reducing sugars and color of the brown sugar.

\section{Materials and Methods}

\subsection{Brown Sugar Processing}

Brown sugars were processed with variation in $\mathrm{pH}\left(5.5\right.$ and 7.0), temperature $\left(118\right.$ and $\left.128^{\circ} \mathrm{C}\right)$ and sugar cane (RB92579 and RB965917). Treatments were conducted in two periods of the year (July - medium, and October - late), numbering 16 treatments.

The brown sugars were produced in $10 \mathrm{~L}$ metallic containers on workbench stoves. For the production, six liters of sugar cane juice were used, and $\mathrm{pH}$ was adjusted with the aid of limewater and a potentiometer, until the liming the juice to $\mathrm{pH} 7.0$ (Figure 1).

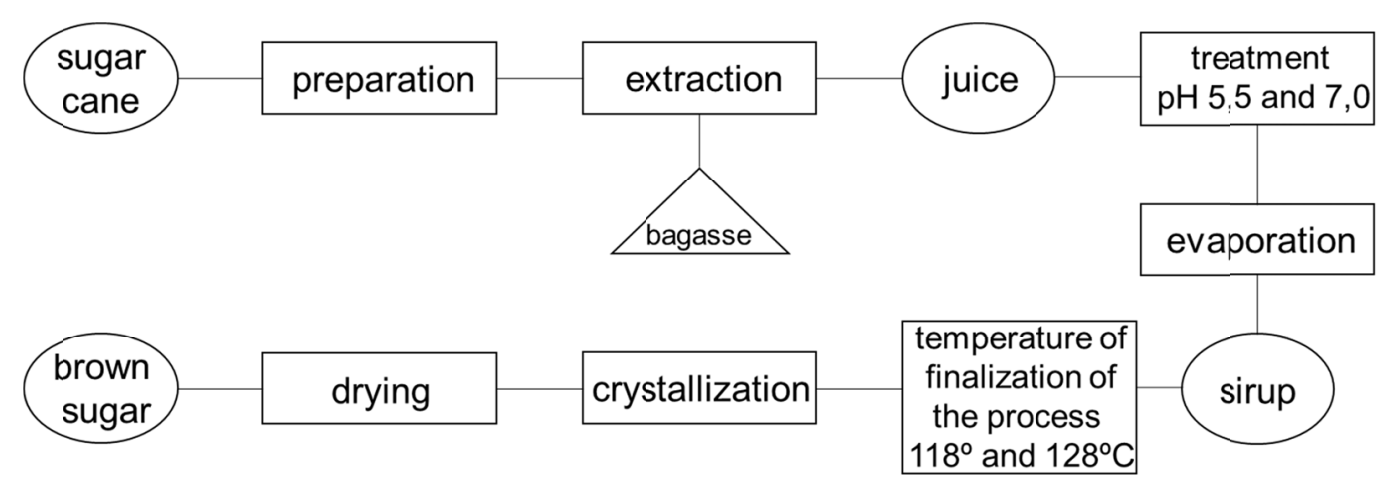

Figure 1. Flow chart of brown sugars production

\subsection{Physicochemical Analyses}

The physicochemical analyses were carried out, in triplicate, in the Laboratory of Analysis and Technological Simulation (LAST). The analyzed pyshicochemical parameters were moisture, which was analyzed using the gravimetric method by weight loss after drying at $100-105{ }^{\circ} \mathrm{C}$, according to the Instituto Adolfo Lutz [IAL] (2005); polarization (Pol), according to the ICUMSA methods (2001); conductivity ashes, measured by the conductivity of the $5 \%(\mathrm{~m} / \mathrm{m})$ sugar solution (ICUMSA, 2011); spectrophotometric color, by the absorbency of the $1 \%(\mathrm{~m} / \mathrm{v})$ brown sugar solution in $420 \mathrm{~nm}$ wavelength; and reducing sugars (RS) and total reducing sugars (TRS), quantified via Lane-Eynon method (FERMENTEC, 2003).

\subsection{Sensory Analysis}

The work was approved by the UFSCar Ethics Committee, according to Certificate for Ethics Assessment (CAAE) nº17964513.3.0000.5504.

The sensory analysis was carried out in the Laboratory of Sensory Analysis of Centro de Ciências Agrárias (UFSCar). The samples of brown sugar ( $20 \mathrm{~g})$ were served in coded transparent glasses together with mineral 
water. To prepare the samples, the sugars produced in the medium period were homogenized with the ones produced in the late period, both belonging to the same treatment.

Twenty-five participated of the ordering test of difference and preference (ABNT, 1994). The samples were presented and the judge was asked to classify them in ascending order of intensity for each of the following attributes: color (light - dark), granularity (thin - thick), cane aroma (weak - strong), sweet aroma (weak strong), sweet flavor (weak - strong), bitter flavor (weak - strong), solubility of the sugar in the mouth (slow fast) and dry texture (little - much). At last, the ordering test of preference (least preferred - most preferred).

The sensory attributes used in the ordering test were chosen through the utilization of the 8 samples in 4 sessions ( 2 samples at a time) by the Method Grid described by Kelly (1955), mentioned by Moskowitz (1983). The selection criteria attribute was the most mentioned, that is, when more than a half of the judges reported the same attribute.

\subsection{Statistic Analyses}

The statistic design was randomized in blocks (seasons) in factorial scheme 2 (variety) $\times 2(\mathrm{pH}) \times 2$ (temperature). The data were submitted to the analysis of variance (ANOVA) in its simplest form, and the Tukey's test was used as multiple comparisons test. The adopted significance level was $5 \%$, and all the analyses were carried out using the R software, 3.0.1 version. The ordening test data were evaluated using the Friedman test (5\% of probability), with the Newell and MacFarlane (1987).

\section{Results and Discussion}

\subsection{Pyshicochemical Analyses}

Table 1 presents the results of moisture, ashes, Pol, color, RS, and TRS of the varieties that were harvested in the different ripening periods, medium (July) and late (October), of the eight treatments.

Table 1. Average results of the physicochemical analyses of brown sugar samples in the medium period (July) and late period (October)

\begin{tabular}{|c|c|c|c|c|c|c|c|c|}
\hline Variety & $\mathrm{pH}$ & Temperature $(\%)$ & Moisture (\%) & Ashes $(\%)$ & Pol & Color & RS (\%) & TRS (\%) \\
\hline \multicolumn{9}{|c|}{ Medium Period } \\
\hline RB92579 & 5.5 & $118^{\circ} \mathrm{C}$ & 7.4 & 1.60 & 83.4 & 2803 & 8.7 & 93 \\
\hline RB92579 & 5.5 & $128^{\circ} \mathrm{C}$ & 3.3 & 1.70 & 80.1 & 4520 & 10.4 & 97 \\
\hline RB92579 & 7.0 & $118^{\circ} \mathrm{C}$ & 6.7 & 1.80 & 85.7 & 3495 & 6.7 & 99 \\
\hline RB92579 & 7.0 & $128^{\circ} \mathrm{C}$ & 3.2 & 1.80 & 84.5 & 4268 & 8.2 & 97 \\
\hline RB965917 & 5.5 & $118^{\circ} \mathrm{C}$ & 5.6 & 1.30 & 87.7 & 2245 & 7.1 & 97 \\
\hline RB965917 & 5.5 & $128^{\circ} \mathrm{C}$ & 3.9 & 1.30 & 85.4 & 2360 & 8.0 & 98 \\
\hline RB965917 & 7.0 & $118^{\circ} \mathrm{C}$ & 6.2 & 1.30 & 89.9 & 2253 & 4.0 & 96 \\
\hline RB965917 & 7.0 & $128^{\circ} \mathrm{C}$ & 3.6 & 1.30 & 89.4 & 2293 & 3.9 & 97 \\
\hline \multicolumn{9}{|c|}{ Later Season } \\
\hline RB92579 & 5.5 & $118^{\circ} \mathrm{C}$ & 5.1 & 1.10 & 85.9 & 1160 & 6.3 & 100 \\
\hline RB92579 & 5.5 & $128^{\circ} \mathrm{C}$ & 3.9 & 1.10 & 83.0 & 1718 & 8.4 & 98 \\
\hline RB92579 & 7.0 & $118^{\circ} \mathrm{C}$ & 4.3 & 1.20 & 90.8 & 1460 & 2.1 & 99 \\
\hline RB92579 & 7.0 & $128^{\circ} \mathrm{C}$ & 2.9 & 1.20 & 87.6 & 1913 & 5.1 & 100 \\
\hline RB965917 & 5.5 & $118^{\circ} \mathrm{C}$ & 6.2 & 0.86 & 90.0 & 0895 & 4.7 & 100 \\
\hline RB965917 & 5.5 & $128^{\circ} \mathrm{C}$ & 3.8 & 0.70 & 83.6 & 1400 & 8.9 & 100 \\
\hline RB965917 & 7.0 & $118^{\circ} \mathrm{C}$ & 5.4 & 0.97 & 92.0 & 0905 & 2.4 & 100 \\
\hline RB965917 & 7.0 & $128^{\circ} \mathrm{C}$ & 2.3 & 0.97 & 89.9 & 1335 & 4.2 & 100 \\
\hline
\end{tabular}

Note. RS: reducing sugars; TRS: total reducing sugars.

According to the results, in the ratio of $\mathrm{pH}$ and temperature for each treatment, there is a tendency in the physicochemical behavior of both attributes for the two periods.

Regarding the moisture, the increase in the process finalization temperature caused a decrease of the the sugars' moisture percentage. Also, there was a direct influence of the juice's acidity on the sugar's moisture, since the juices that were neutralized up to $\mathrm{pH} 7.0$ presented less moisture when compared to the treatments with $\mathrm{pH} 5.0$ at 
the same temperature. This phenomenon can be explained by the higher proportion of reducing sugars (RS) in the sugars whose juices were vaporized in their natural $\mathrm{pH}$ (5.5). The acid environment corroborates, together with the heating, the sucrose hydrolysis and, consequently, the generation of RS, which is hygroscopic.

Significant differences were verified in the parameters $\mathrm{pH} 7.0\left(4.3^{\mathrm{a}}\right) ; 5.5\left(4.9^{\mathrm{b}}\right)$ and Temperature $118{ }^{\circ} \mathrm{C}\left(5.9^{\mathrm{a}}\right)$; $128^{\circ} \mathrm{C}\left(3.4^{\mathrm{b}}\right)$. According to Lopes and Borges (1998), to meet the specifications, a good-quality brown sugar must have a maximum of $5.0 \%$ of moisture, as it provides sensory and microbiological disadvantages when risen, such as the caking of sugar and the decrease in the product's shelf life due to the increase of water activity and, consequently, the easiness for microbial activity (P. A. Bobbio \& F. O. Bobbio, 1995).

Regarding the ashes, the slight difference that was observed in some results can be attributed to the inorganic compounds that were incorporated with the addition of limewater for the liming of the juice's $\mathrm{pH}$, since there was a small increase in the amountamount of ashes in the sugar that had the juices evaporated at $\mathrm{pH} 7.0$, compared to its correspondent evaporated at a natural $\mathrm{pH}$.

For the same atribute, significant differences of $\mathrm{pH}-7.0\left(1.3^{\mathrm{a}}\right) ; 5.5\left(1.2^{\mathrm{b}}\right)$ and Variety $-\mathrm{RB} 965917\left(1.1^{\mathrm{a}}\right)$; RB92579 $\left(1.4^{\mathrm{b}}\right)$ were noticed. According to the authors, to meet the specifications, a good-quality brown sugar must have a maximum of $2.4 \%$ of ashes. A large amount of ashes modifies the flavor of the product, giving it a bitter or salt flavor, what harms its acceptability.

The proportion of sucrose, represented by the Polatization $(\mathrm{Pol})$ value, was significantly different for the attributes $\mathrm{pH}-7.0\left(88.7^{\mathrm{a}}\right) ; 5.5\left(84.9^{\mathrm{b}}\right)$, Temperature $-118^{\circ} \mathrm{C}\left(88.2^{\mathrm{a}}\right) ; 128^{\circ} \mathrm{C}\left(85.4^{\mathrm{b}}\right)$ and Variety $-\mathrm{RB} 965917$ $\left(88.5^{\mathrm{a}}\right)$; RB92579 $\left(85.1^{\mathrm{b}}\right)$. The data also showed an increase in Pol for the samples from the late period, compared to the ones from the medium period, what was expected due to the sugar cane ripening.

As noticed ratio between $\mathrm{pH}$ and Temperature for each treatment, there was a decrease in Pol for the treatments of higher temperature and with the juice's natural $\mathrm{pH}$ (5.5), what explains again the chemical phenomenon of sucrose hydrolysis in reducing sugars. The variable Variety also influences on the proportion of sucrose, since the varieties present different phenotypic properties.

These results showed that the brown sugar Polarization is closely related to the variations of $\mathrm{pH}$, temperature and variety of the cane that was used in the sugar production. To Lopes and Borges (1998), to meet the specifications, a good-quality brown sugar must have a minimum of $85^{\circ} \mathrm{Z}$ of Polarization.

Regarding the color, besides showing varietal influence, the higher the temperature is and the lower the juice $\mathrm{pH}$ is, it shows a tendency to the darkening of the sugar. Therefore, there were, statistically, significant differences of the attributes Temperature - $128\left(1985.83^{\mathrm{a}}\right) ; 118\left(2475.78^{\mathrm{b}}\right)$ and Variety - RB965917 (1710.6 $)$; RB92579 $\left(2802.0^{\mathrm{b}}\right)$.

The reducing sugars, originated in the sucrose hydrolysis due to the high temperatures, are one of the precursors of the brown sugar's color, since they generate compounds that result from the reaction of these sugars with amino acids (Maillard reaction).

Another importante factor in the color of the brown sugar is the structural modification, due to $\mathrm{pH}$ limings of natural pigments that are present in the sugar cane. The flavonoid group is the most critical one to the sugar processing and the responsible for up to $30 \%$ of the color of raw sugar with $\mathrm{pH}$ 7.0. The flavonoids can modify its coloration according to the environment's pH (ARAÚJO, 2001).

As mentioned, the values of Reducing Sugars (RS) increased in the treatments with higher temperature and lower $\mathrm{pH}$, which are related to the sucrose's hydrolysis in glucose and fructose. The variables Variety and Period of the year are factors that also influence on this characteristic. Statistically, for the variable RS, there was a significant difference in the attributes $\mathrm{pH}-5.5\left(7.84^{\mathrm{a}}\right) ; 7.0\left(4.43^{\mathrm{b}}\right)$, Temperature $-128^{\circ} \mathrm{C}\left(7.09^{\mathrm{a}}\right) ; 118^{\circ} \mathrm{C}\left(5.19^{\mathrm{b}}\right)$ and Variety - RB92579 $\left(6.91^{\mathrm{a}}\right)$; RB965917 $\left(5.38^{\mathrm{b}}\right)$. According to Lopes and Borges (1998), to meet the specifications, a good-quality brown sugar must have a maximum of $3.5 \%$ of reducing sugars.

For the variable TRS, the interection was noticed only in the factor Period of the year: the higher concentrations of TRS are found in the late period, due to the sugar cane ripening. According to the authors, to meet the specifications, a good-quality brown sugar must have a minimum of $90 \%$ of total reducing sugars. The factor Period of the year was significant for all the variables.

The study conducted by Mujica et al. (2008) states that the sugar cane variety had great importance in the quality of brown sugar, since it influenced the amount of reducing sugars, in the $\mathrm{pH}$ and color of the final product, concluding still, that is necessary to drying the product after crystallization, for the monitoring of humidity. The present study shows that it is possible to produce sugars with color, moisture content and reducing sugars 
quantity controlable, just using different varieties and combining appropriate process temperature and $\mathrm{pH}$. Therefore, there would be no more needs for further processes to ensure the quality of the product.

\subsection{Sensory Analyses}

The results that were obtained in the ordering test for difference and preference show that the samples had significant differences $(\mathrm{p} \leq 0.05)$ among themselves in all the attributes, including global preference (Tables 2 and 3).

Regarding the attribute color, the samples differed among varieties, and, inside each variety, they did not present significant differences related to the treatments. Consequently, it is clear that the final product color was related to the variety of sugar cane used in the brown sugar production and that the modifications that were caused by the different treatments were not visibly noticed, but only by spectrophotometry.

For the attribute granularity, there was a significant difference among the varieties, since the brown sugar that was produced with the variety 2 (RB92579) distinguished itself with a thinner texture than the variety 1 (RB965917).

Regarding the sugar cane aroma, the samples of brown sugar $\mathrm{V}_{1} \mathrm{~T}_{128} \mathrm{pH}_{5,5}$ and $\mathrm{V}_{1} \mathrm{~T}_{128} \mathrm{pH}_{7,0}$ presented the highest sums and, consequently, higher intensity of the sugar cane aroma, in opposition to the samples $\mathrm{V}_{1} \mathrm{~T}_{118} \mathrm{pH}_{5,5}$, $\mathrm{V}_{2} \mathrm{~T}_{118} \mathrm{pH}_{5.5}$ and $\mathrm{V}_{2} \mathrm{~T}_{128} \mathrm{pH}_{5.5}$, which presented the lowest sums.

About the sweet aroma, the samples of the variety RB965917 presented the highest sums, being characterized as having the most pronounced sweet aroma, while the samples of the variety RB92579 presented the lowest sum. Thus, it is possible to consider the existence of a ratio between the sugar cane variety and the final product's sweet aroma.

Table 2. Sum of the orders of the sensory attributes of appearance and aroma to the studied brown sugars

\begin{tabular}{|c|c|c|c|c|}
\hline \multirow{2}{*}{ Samples } & \multicolumn{2}{|c|}{ Appearance } & \multicolumn{2}{|c|}{ Aroma } \\
\hline & Color & Granularity & Cane & Sweet \\
\hline $\mathrm{V}_{1} \mathrm{~T}_{118} \mathrm{pH}_{5.5}$ & $44^{b}$ & $193^{\mathrm{a}}$ & $89^{b}$ & $118^{\mathrm{abc}}$ \\
\hline $\mathrm{V}_{1} \mathrm{~T}_{128} \mathrm{pH}_{5.5}$ & $48^{\mathrm{b}}$ & $160^{\mathrm{ab}}$ & $153^{\mathrm{a}}$ & $142^{\mathrm{ab}}$ \\
\hline $\mathrm{V}_{1} \mathrm{~T}_{118} \mathrm{pH}_{7.0}$ & $75^{b}$ & $152^{\mathrm{ab}}$ & $125^{\mathrm{ab}}$ & $136^{\mathrm{ab}}$ \\
\hline $\mathrm{V}_{1} \mathrm{~T}_{128} \mathrm{pH}_{7.0}$ & $83^{b}$ & $132^{\mathrm{bc}}$ & $151^{\mathrm{a}}$ & $163^{\mathrm{a}}$ \\
\hline $\mathrm{V}_{2} \mathrm{~T}_{118} \mathrm{pH}_{5.5}$ & $162^{\mathrm{a}}$ & $45^{\mathrm{d}}$ & $77^{\mathrm{b}}$ & $74^{\mathrm{c}}$ \\
\hline $\mathrm{V}_{2} \mathrm{~T}_{128} \mathrm{pH}_{5.5}$ & $171^{\mathrm{a}}$ & $64^{\mathrm{d}}$ & $91^{\mathrm{b}}$ & $78^{\mathrm{c}}$ \\
\hline $\mathrm{V}_{2} \mathrm{~T}_{118} \mathrm{pH}_{7.0}$ & $140^{\mathrm{a}}$ & $69^{\mathrm{d}}$ & $105^{\mathrm{ab}}$ & $95^{\mathrm{bc}}$ \\
\hline $\mathrm{V}_{2} \mathrm{~T}_{128} \mathrm{pH}_{7.0}$ & $177^{\mathrm{a}}$ & $85^{\mathrm{cd}}$ & $109^{\mathrm{ab}}$ & $92^{\mathrm{bc}}$ \\
\hline
\end{tabular}

Note. $\mathrm{V}_{1}$ : variety $\mathrm{RB} 965917 ; \mathrm{V}_{2}$ : variety $\mathrm{RB} 92579$. Values followed by the same letters on the horizontal axis do not differ significantly ( $\mathrm{p} \geq 0.05)$. Minor difference $\geq 53$.

For the sweet flavor, the sample $\mathrm{V}_{1} \mathrm{~T}_{128} \mathrm{pH}_{7.0}$ presented the highest sum, differing significantly from the sample $\mathrm{V}_{2} \mathrm{~T}_{118} \mathrm{pH}_{5,5}$, which presented the lowest sum and, consequently, lower intensity of sweet flavor. Regarding this attribute, it is not possible to establish a ratio between variety and treatment, because the other samples do not differ among themselves statistically. For bitter flavor, the sample $\mathrm{V}_{1} \mathrm{~T}_{118} \mathrm{pH}_{7.0}$ presented the highest sum, differing from the samples $\mathrm{V}_{2} \mathrm{~T}_{128} \mathrm{pH}_{5.5}$ and $\mathrm{V}_{2} \mathrm{~T}_{118} \mathrm{pH}_{7.0}$, of lower sums. Nevertheless, the three samples do not differ significantly from the others.

Regarding the solubility, the sample $\mathrm{V}_{2} \mathrm{~T}_{118} \mathrm{pH}_{5.5}$ presented the highest sum, that is, it is the sample that was characterized with higher speed of solubility in the mouth, differing significantly from the samples of variety 1 . The sample $\mathrm{V}_{1} \mathrm{~T}_{118} \mathrm{pH}_{5.5}$ presented, inside the variety 1, the lowest sum. It is possible to establish a ratio between solubility and texture of the sugar, because the variety 1 presented the samples with the lowest sum for solubility and the highest sum for granularity, while the samples of variety 2 presented an opposed behavior, with higher sum for solubility and lower sum for granularity.

For dry texture, there was a slight variation. The sample $\mathrm{V}_{1} \mathrm{~T}_{118} \mathrm{pH}_{5.5}$ presented the highest sum, differing significantly from the sample $\mathrm{V}_{2} \mathrm{~T}_{118} \mathrm{pH}_{7.0}$, which presented the lowest sum. Both of them do not differ significantly from the other samples. 
Regarding the global preference, the samples of variety 2 presented the highest sum, differing significantly only from the sample $\mathrm{V}_{1} \mathrm{~T}_{118} \mathrm{pH}_{5.5}$, inside the variety 1, which presented the lowest sum, being, therefore, the least favorite.

Table 3. Sum of the orders of the sensory attributes of brown sugars

\begin{tabular}{|c|c|c|c|c|c|}
\hline \multirow{2}{*}{ Samples } & \multicolumn{2}{|c|}{ Flavor } & \multicolumn{2}{|c|}{ Texture } & \multirow{2}{*}{ Preference Global } \\
\hline & Sweet & Bitter & Solubility & Dry & \\
\hline $\mathrm{V}_{1} \mathrm{~T}_{118} \mathrm{pH}_{5.5}$ & $122^{\mathrm{ab}}$ & $119^{\mathrm{ab}}$ & $58^{\mathrm{c}}$ & $139^{\mathrm{a}}$ & $69^{\mathrm{b}}$ \\
\hline $\mathrm{V}_{1} \mathrm{~T}_{128} \mathrm{pH}_{5.5}$ & $130^{\mathrm{ab}}$ & $126^{\mathrm{ab}}$ & $98^{\mathrm{bc}}$ & $124^{\mathrm{ab}}$ & $112^{\mathrm{ab}}$ \\
\hline $\mathrm{V}_{1} \mathrm{~T}_{118} \mathrm{pH}_{7.0}$ & $117^{\mathrm{ab}}$ & $150^{\mathrm{a}}$ & $96^{\mathrm{bc}}$ & $106^{\mathrm{ab}}$ & $91^{\mathrm{ab}}$ \\
\hline $\mathrm{V}_{1} \mathrm{~T}_{128} \mathrm{pH}_{7.0}$ & $161^{\mathrm{a}}$ & $115^{\mathrm{ab}}$ & $96^{\mathrm{bc}}$ & $122^{\mathrm{ab}}$ & $108^{\mathrm{ab}}$ \\
\hline $\mathrm{V}_{2} \mathrm{~T}_{118} \mathrm{pH}_{5.5}$ & $62^{\mathrm{c}}$ & $111^{\mathrm{ab}}$ & $160^{\mathrm{a}}$ & $102^{\mathrm{ab}}$ & $139^{\mathrm{a}}$ \\
\hline $\mathrm{V}_{2} \mathrm{~T}_{128} \mathrm{pH}_{5.5}$ & $96^{\mathrm{bc}}$ & $95^{\mathrm{b}}$ & $141^{\mathrm{ab}}$ & $111^{\mathrm{ab}}$ & $135^{\mathrm{a}}$ \\
\hline $\mathrm{V}_{2} \mathrm{~T}_{118} \mathrm{pH}_{7.0}$ & $109^{\mathrm{abc}}$ & $83^{\mathrm{b}}$ & $129^{\mathrm{ab}}$ & $85^{\mathrm{b}}$ & $122^{\mathrm{a}}$ \\
\hline $\mathrm{V}_{2} \mathrm{~T}_{128} \mathrm{pH}_{7.0}$ & $98^{\mathrm{bc}}$ & $98^{\mathrm{ab}}$ & $122^{\mathrm{ab}}$ & $111^{\mathrm{ab}}$ & $124^{\mathrm{a}}$ \\
\hline
\end{tabular}

Note. $\mathrm{V}_{1}$ : variety $\mathrm{RB} 965917 ; \mathrm{V}_{2}$ : variety $\mathrm{RB} 92579$. Values followed by the same letters on the horizontal axis do not differ significantly $(\mathrm{p} \geq 0.05)$. Minor difference $\geq 53$.

\section{Conclusion}

$>$ The parameters that were studied $-\mathrm{pH}$, temperature of finalization, period of the year and variety - are important in the quality control of brown sugar production.

$>\quad$ The sugars with the best physicochemical parameters presented neutral juice $\mathrm{pH}(7.0)$ and temperature of finalization at $118^{\circ} \mathrm{C}$ in the late period for both varieties.

$>$ The sugars that were produced with the ripest sugar cane (late period) presented physicochemical characteristics that increase their shelf life, since they presented a smaller amount of RS and lower moisture, in a general way.

$>\quad$ The results that were obtained in the ordering analysis show that the treatments differed significantly ( $\mathrm{p} \leq$ 0.05) among themselves in almost all the attributes, including global preference, what proves the heterogeneity among the samples.

$>$ The variety presented great sensory influence on the attributes color, granularity, sweet aroma, sweet flavor, and solubility, in which there were at least two samples that differed significantly compared to the other variety. In this case, the variety RB965917 $\left(\mathrm{V}_{1}\right)$ can be considered as the variety of a clearer brown sugar, with bigger granules, more intense sweet aroma and flavor and low solubility.

$>\quad$ It can also be concluded that the choice of the variety of sugar cane used plays a key role to obtain a final product of higher quality, since the data of global preference with higher sum were concentrated in the group of samples of brown sugar of the variety 2 (RB92579), what can mean that the judges prefer a sugar of a darker appearance, smaller granules, less intense sweet aroma and flavorm and high solubility.

\section{References}

ABNT (Associação Brasileira de Normas Técnicas). (1994). Teste de ordenação em análise sensorial. NBR 13170. Rio de Janeiro.

Araújo, E. R., Borges, M. T. M. B., Ceccato-Antonini, S. R., \& Verruma-Bernardi, M. R. (2011). Qualidade de açúcares mascavo produzidos em um assentamento da reforma agrária. Alimentos e Nutrição, 22(4), 617-621.

Araújo, J. M. A. (2001). Química de Alimentos (2nd ed.). Viçosa: Teoria e Prática.

Bobbio P. A., \& Bobbio, F. O. (1995). Química do Processamento de Alimentos (2nd ed.). São Paulo: Varela Ltda.

Durán Rojas, E., Pérez, R., Cardoso, W., \& Pérez, O. (2012). A Colorimetria e aceitação de açúcar mascavo. Temas Agrários, 17(2), 30-42. 
Fermentec. (2003). Métodos analíticos para o controle da produção de açúcar e álcool (3rd ed.). Piracicaba: Fermentec.

IAL (Instituto Adolfo Lutz). (2005). Métodos fisico-químicos para análise de alimentos (4th ed.). Brasília: ANVISA.

ICUMSA. (2011). International Commission for Uniform Methods of Sugar Analysis. ICUMSA methods book. England: Icumsa.

Lopes, C. H., \& Borges, M. T. M. R. (1998). Produção de açúcar mascavorapadura e melado de cana (1st ed.). Rio Grande do Sul: Capacitação Tecnológica para a Cadeia Agroindustrial.

Mezaroba, S., Meneguetti, C. C., \& Groff, A. M. (2010). Processo de produção do açúcar de cana e os possíveis reaproveitamentos dos subprodutos e resíduos resultantes do sistema. IV Encontro de Engenharia de Produção Agroindustrial (FECICLAM). Campo Mourão/PR, Brasil.

Moskowitz, H. R. (1983). Product testing and sensory evaluation of foods. Marketing and $R \&$ \& Approaches (p. 605). Westport: Food and Nutrition Press.

Mosquera, S. A., Carrera, J. E., \& Villada, H. S. (2007). Variables que afectan la calidad de la panela procesada en el departamento del cauca. Facultad Ciencias Agropecuarias, 5(1), 17-27.

Mujica, M. V., Guerra, M., \& Soto, N. (2008). Efecto de la variedad, lavado de la caña y temperatura de punteo sobre la calidad de la panela granulada. Interciencia, 33(8), 598-602.

Newell, G. J., \& Macfarlane, J. D. (1987). Expanded tables for multiple comparison procedures in the analysis of ranked data. Journal of Food Science, 52(6), 1721-1725. https://doi.org/10.1111/j.1365-2621.1987.tb 05913.x

Verruma-Bernardi, M. R., Borges, M. T. M. R., Lopes, C. H., Della-Modesta, R. C., \& Ceccato-Antonini, S. R. (2007). Avaliação Microbiológica, Físico-Química e Sensorial de Açúcares Mascavos Comercializados na Cidade de São Carlos, SP. Brazilian Journal of Food Technology, 10(3), 205-211.

Verruma-Bernardi, M. R., Silva, T. G. E. R., Borges, M. T. M. R., Lopes, C. H., \& Deliza, R. (2010). Avaliação sensorial de açúcar mascavo. Brazilian Journal of Food Technology, 14(1), 29-38.

\section{Copyrights}

Copyright for this article is retained by the author(s), with first publication rights granted to the journal.

This is an open-access article distributed under the terms and conditions of the Creative Commons Attribution license (http://creativecommons.org/licenses/by/4.0/). 